\title{
A Test of Taxonomic and Biogeographic Predictivity: Resistance to Soft Rot in Wild Relatives of Cultivated Potato
}

\author{
Yong Suk Chung, Karsten Holmquist, David M. Spooner, and Shelley H. Jansky
}

First author: Department of Horticulture, and second, third, and fourth authors: United States Department of Agriculture-Agricultural Research Service and Department of Horticulture, University of Wisconsin, 1575 Linden Drive, Madison 53706. Accepted for publication 2 September 2010.

\section{ABSTRACT}

Chung, Y. S., Holmquist, K., Spooner, D. M., and Jansky, S. H. 2011. A test of taxonomic and biogeographic predictivity: Resistance to soft rot in wild relatives of cultivated potato. Phytopathology 101:205-212.

The concept that traits should be associated with related organisms and that nearby populations of the same species are likely to be more similar to each other than to populations spread far apart has long been accepted. Consequently, taxonomic relationships and biogeographical data are commonly believed to have the power to predict the distribution of disease resistance genes among plant species. In this study, we test claims of such predictivity in a group of widely distributed wild potato species. There was no clear association between resistance to soft rot and taxonomic relationships. However, we have found some associations between resistance to soft rot and environmental data such as annual precipitation and annual mean temperature. In addition, we have noted that high levels of resistance are mostly found in species with high levels of phenotypic plasticity. The three most resistant species were Solanum paucijugum, S. brevicaule, and S. commersonii.

Additional keywords: Pectobacterium, selection pressure.
Despite the general acceptance of taxonomic and biogeographic predictivity hypotheses, they have not been empirically tested until recently, where they have been carried out in potato (11-13). Wild potato species (tuber-bearing species in Solanum L. sect. Petota Dumort.) provide a good model system for this type of study because they represent a highly diverse and accessible germplasm resource (6). Wild potato species are found in a tremendously diverse array of environments that include cold high grasslands of the Andes, hot semi-deserts and seasonally dry habitats, humid subtropical to temperate mountain rain forests, cultivated fields, and even epiphytic niches. They grow from sea level to over $4,300 \mathrm{~m}$. Traditional taxonomic studies have partitioned section Petota into distinct taxonomic series (6). Recent molecular phylogenies, however, divide section Petota into four clades based on plastid DNA restriction site data or three clades based on nuclear DNA data, with many of the polyploids supported as allopolyploids $(26,29)$. These molecular phylogenies show little relationship to previously established taxonomic series. Wild Solanum spp. exist in a ploidy series from diploid to hexaploid, and there are both inbreeding and outbreeding species. A strong biological isolating mechanism separating large groups of species results in endosperm death in crosses between species with different "endosperm balance numbers" (EBNs) (5). Ploidy/EBN values in section Petota include 2x (1EBN), 2x (2EBN), 4x (2EBN), 4x (4EBN), and 6x (4EBN).

Previous studies based on a common set of species have found that neither taxonomic relationships nor biogeographic factors consistently predict resistance to two foliar fungal pathogens

Corresponding author: S. H. Jansky; E-mail address: shelley.jansky@ars.usda.gov

* The $\boldsymbol{e}$-Xtra logo stands for "electronic extra" and indicates that the online version contains four supplemental figures and two supplemental tables.

doi:10.1094/PHYTO-05-10-0139

This article is in the public domain and not copyrightable. It may be freely reprinted with customary crediting of the source. The American Phytopathological Society, 2011 causing white mold and early blight $(11,12)$, and the defoliating insect, Colorado potato beetle (13). Another study reported a similar lack of predictivity but the data were gathered from a variety of published and unpublished sources using different screening methods (31). However, we have not tested predictivity for a soilborne bacterial pathogen, which could produce different results. In the current study, we screened a wide range of wild potato species for resistance to tuber soft rot, caused by Pectobacterium (formerly Erwinia) carotovorum subsp. carotovorum to determine whether bacterial disease resistance in wild potato germplasm can be predicted using taxonomic or biogeographic data.

\section{MATERIALS AND METHODS}

Production of tubers. We obtained botanical seed from the U.S. Potato Gene Bank (NRSP-6), and planted between one and five accessions (populations) of each of 38 species, for a total of 123 accessions. All seed were sown in January 2008, plants were grown in a greenhouse, and tubers were harvested in May 2008. Fifteen plants per accession and three tubers per plant were evaluated for soft rot resistance. Accessions were representative of a broad geographic area and a wide range of habitats (Fig. 1). Our study included 13 of the 19 tuber-bearing series of Hawkes and all four clades as determined by plastid and nuclear DNA data $(26,29,30,32)$ (Fig. 2). These accessions represent the range of distribution of wild Solanum spp. (Fig. 3).

Disease resistance screening. $P$. carotovorum isolate WPP14 was cultured and $3 \mu \mathrm{l}$ of prepared bacterial suspension $(3.0 \times$ $10^{8} \mathrm{CFU} / \mathrm{ml}$ ) was inoculated into each tuber in a hole with a depth of $5 \mathrm{~mm}$ created by a pipette tip (34). Then, the diameter of decay was measured after a 72 -h incubation in the dark at $100 \%$ relative humidity and $25^{\circ} \mathrm{C}$.

Statistical analyses of taxonomic traits. Some tubers were so small that they completely rotted after inoculation. Consequently, the true resistance value could not be determined. The width of decay of these small susceptible tubers was given a value of $9 \mathrm{~mm}$ based on the least significant difference from the mean of tuber 
soft rot resistance of all accessions. Consequently, resistance data were considered to be censored. Censored data are most appropriately analyzed using nonparametric methods based on rank scores. The Kruskal-Wallis test (16) was used for comparisons among more than two groups. To determine the relative contributions of species, accessions, and individual plants to the observed variation, a linear model was fit, with species and accessions considered to be random effects. The contribution due to individual plants was reflected in the residual variability.

Association between biogeographical variables and soft rot resistance. We used distribution-free tests of association between the explanatory biogeographical variables annual mean temperature (AMT) and annual precipitation (AP) and the dependent variable of soft-rot resistance score (15). First, we calculated the median resistance score $(\mathrm{mm})$ for each replicate of each plant tested for soft rot resistance. Therefore, the base sample size $(n)$ for each test within a species was the number of plants tested for soft rot resistance. Next, we simulated variation in AMT and AP for each plant and its median resistance score by generating 100 random draws from the 30-year distribution of AMT and AP (22) associated with the accession from which each plant was derived. Then, we generated 1,000 bootstrap data sets of size $n$ for each species. For each of the 1,000 bootstrap samples, we calculated Kendall's Tau (22). Finally, we assessed the significance of the association between soft rot resistance and both AMT and AP

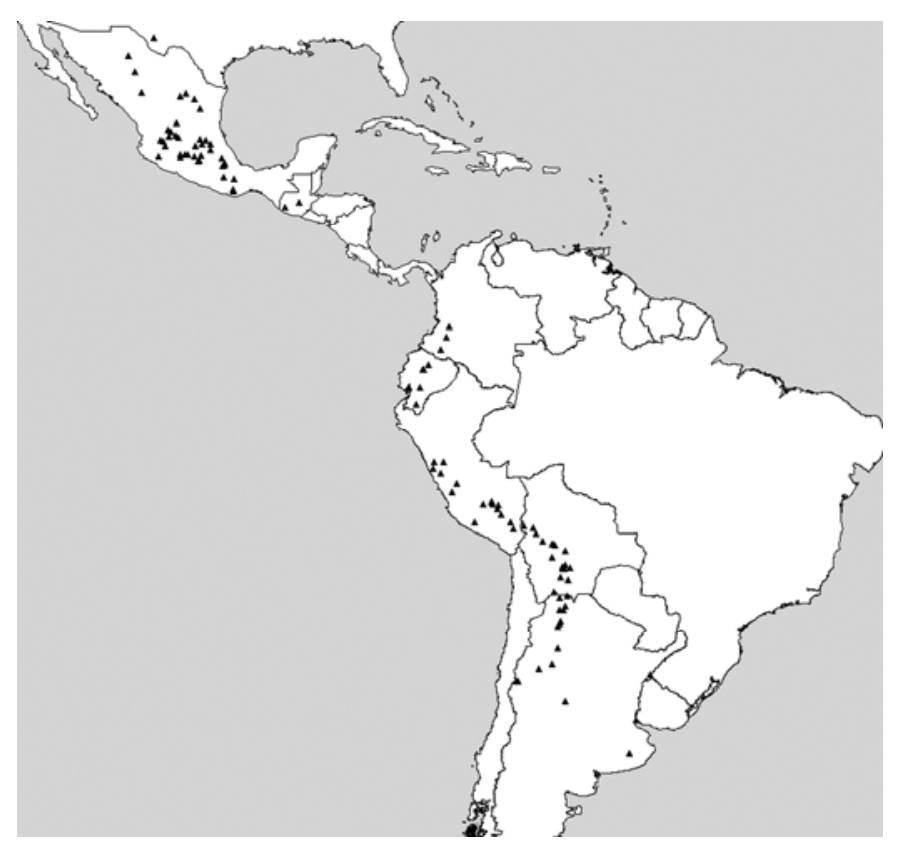

Fig. 1. Geographic localities of accessions. Each triangle indicates where an accession was collected. using the median Tau from the 1,000 bootstrap replicates in order to calculate Kendall's $\mathrm{K}$ statistic for comparison with a table of the upper-tail probabilities for the null distribution of the Kendall $\mathrm{K}$ statistic (9). The data set is available and was constructed as CRU 0.5 Degree Dataset from sources at http://www.sage.wisc.edu/ atlas/maps.php (22).

\section{RESULTS AND DISCUSSION}

As in previous studies for other traits, this study detected statistically significant differences in resistance levels among species, taxonomic series, plastid-based molecular clades, ploidy levels, and EBN $(P<0.0001,0.0001,0.01,0.05$, and 0.05, respectively) but not breeding systems $(P=0.079)$. The proportion of variation due to species, accessions, clones, and individual tubers within a plant was estimated and the largest source of variability was species while the smallest was individual tubers from a single plant (Supplemental Table 1). Sometimes, however, variation was large among accessions within species and among plants within accessions (Table 1), implying that it is important to focus on accessions and individual plants rather than species.

The three most resistant species were Solanum paucijugum, $S$. brevicaule, and $S$. commersonii (Fig. 3). As a group, 8 of the top 10 most resistant species were diploid. However, this ratio is not different from the proportion of diploid species in this study, based on a $\chi^{2}$ test $(P<0.05)$. Also, 2 EBN species were more resistant than $1 \mathrm{EBN}$ or $4 \mathrm{EBN}$ species. In all, 9 of the 10 most resistant species were $2 \mathrm{EBN}$ and this result is not consistent with those from the white mold (11), early blight (12), and Colorado potato beetle (13) resistance studies, where the most resistant species were 1 EBN. There were no significant differences between inbreeding and outcrossing species, although there was a trend toward more resistance in outcrossing species. The most resistant series were series Tuberosa (5 of the 10 most resistant species) and series Conicibaccata (3 of the 10 most resistant species), which is inconsistent with previous studies testing other traits (11-13).

Because the 10 most resistant species were distributed among four series, two clades, two EBN values, and two ploidy levels, there was no consistent relationship between mean resistance score and taxonomic data (Fig. 3). This is similar to previous results obtained for other diseases using wild potato species and wild tomato species $(11-13,27)$.

However, some patterns were detected when species were analyzed individually. Populations within species were exposed to different environments, such as AMT, AP, soil moisture holding capacity, shading, and biotic interactions. A distribution-free test of association between soft rot resistance score for accessions within each species and the most important factors for soft rot severity, AMT and AP (data were collected in 1960 to 1990) (22), confirmed that there often is a relationship between disease resistance and these environmental factors at the accession level

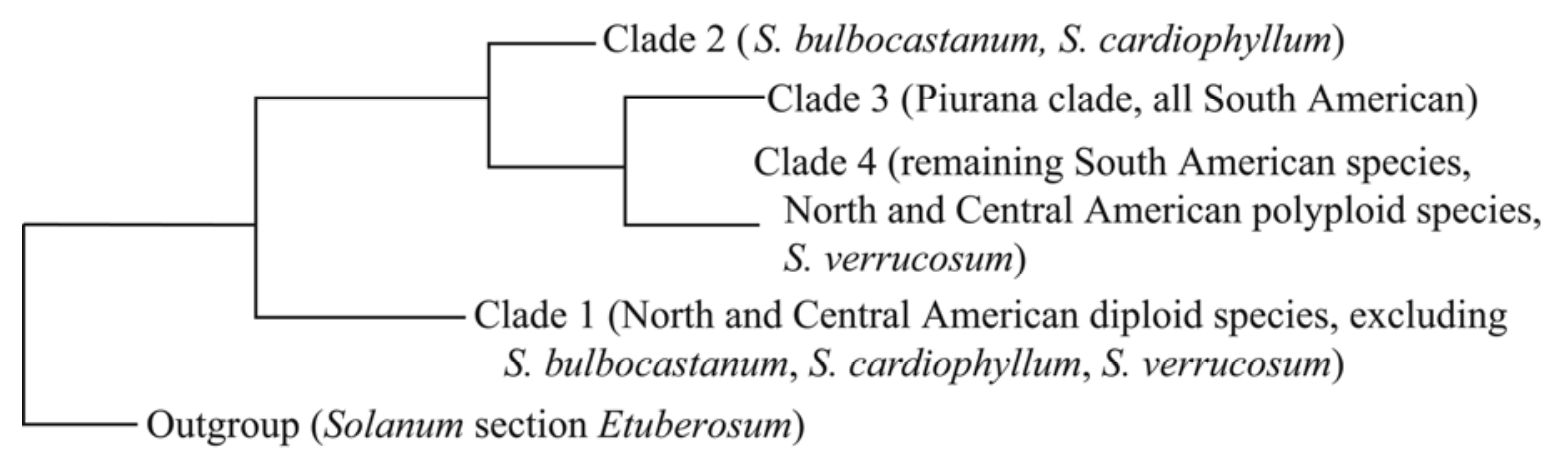

Fig. 2. Cladistic relationships of potato, tomato, and outgroups sensu Spooner and collaborators as described in text, showing the four clades in potato, and outgroups,. 
(Table 2). Among the 28 species for which more than two accessions were analyzed, 25.0 and $53.6 \%$ of the species tested demonstrated a significant association between soft rot resistance and AMT and AP, respectively $(P<0.05)$.

Plots of simulated AMT and AP data show interesting patterns (Fig. 4). Each population of a species may have been exposed to different temperature and precipitation conditions before it was collected. In addition, some locations where accessions were collected may experience a wider range of temperatures or precipitation than others. When the association between AMT or AP and soft rot resistance was significant (Table 2), each accession was exposed to a different range of environmental variation with respect to AMT or AP (Fig. 4). All of the 10 most resistant species (except 2 species that were not tested because each was represented by a single accession) are sensitive to AMT and AP; the accessions within a species form discrete patterns rather than a clustered pattern, as is shown for $S$. brevicaule in Figure 5. Species that inhabit more heterogeneous environments with respect to AMT and, especially, AP may have a higher chance of being exposed to strong selection pressure and, therefore, evolve resistance to soft rot disease.

It is interesting to note that twice as many species showed a significant association between soft rot resistance and AP than between soft rot resistance and AMT. This suggests that AP is a more important factor than AMT; AP is correlated with soil moisture, which is a key factor for soft rot disease spread. When no significant association was found between AP and soft rot resistance, it was largely because either the resistance score or AP did not vary among accessions within a species.

Resistance levels sometimes varied among species with a similar range of AMT and AP. This implies that there may be other environmental interactions leading to selection pressure and, consequently, different levels of fitness in the presence of soft rot disease. For example, the case of $S$. jamesii shows that selection pressure is important for the evolution of disease resistance. $S$. jamesii was collected from a desert area in the southern part of United States. The soilborne pathogen $P$. carotovorum subsp. carotovorum does not survive in this arid environment. Thus, there would be no disease pressure and no selection pressure for the species to evolve resistance (Fig. 3). Consequently, accessions collected in the entire range of this species are consistently susceptible. On the other hand, $S$. verrucosum shows a large variation in resistance scores and is commonly found in a wide range of AMT and AP, leading us to infer that there is more potential for adaptation and the evolution of disease resistance in species possessing adaptation to a wider range of environmental variation.

Plant morphology and habitat information may also provide predictive insights about disease pressure exerted on different species. The most soft-rot-resistant species were generally found in humid, shady, or damp places $(3,6)$. However, resistance levels were not always associated with the expected habitat. For example, the habitat of one of the most susceptible species, $S$. andreanum, is moist and humid and, therefore, favorable for $P$. carotovorum subsp. carotovorum.

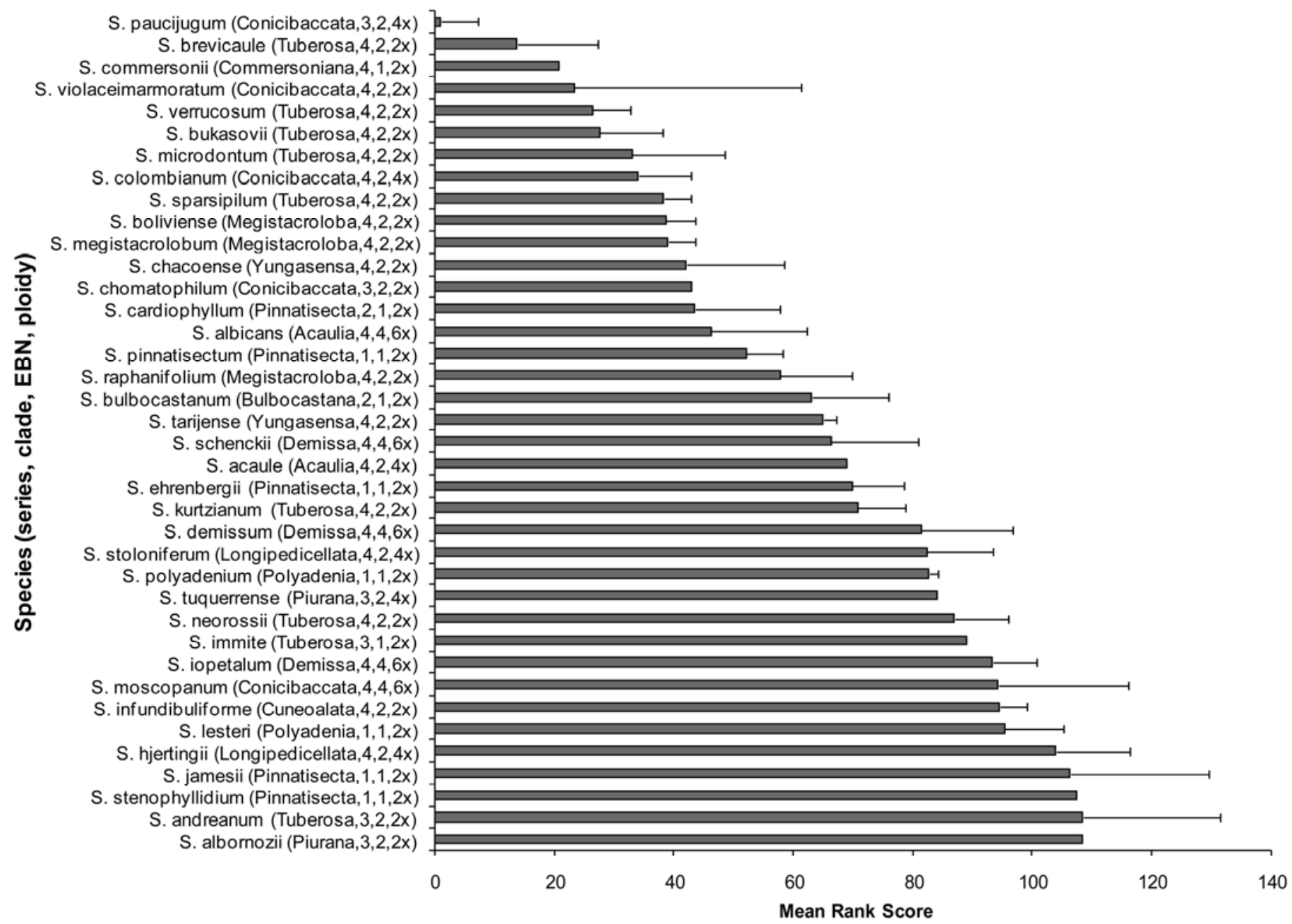

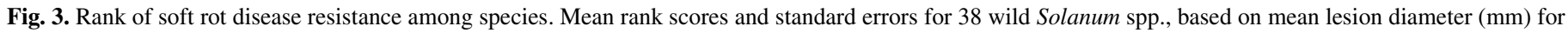

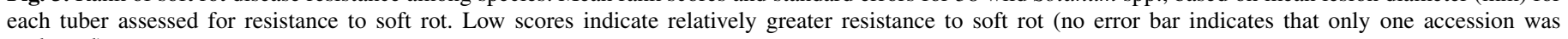
evaluated). 
When habitat information (Supplemental Table 2) $(3,33)$ was combined with plant architecture, resistance levels were more consistently predicted. Plants with a low, spreading habit tend to shade the soil, providing favorable conditions for soilborne bacteria (28). The three most resistant species (S. paucijugum, $S$. brevicaule, and $S$. commersonii) grow in moist habitats and are typically low-growing plants with a spreading growth habit. These factors may have favored selection for a genetically based resistance system in order to survive pathogen pressure in the soil.
A correlation between plant architecture and soilborne fungus disease pressure has been reported in Phaseolus vulgaris (1). In contrast, most susceptible species in favorable habitats for Pectobacterium carotovorum subsp. carotovorum were erect and tall; therefore, they likely experienced less selection pressure.

Disease resistance variation among and even within species is likely to result from complex interactions among the factors that allow plants to survive in the presence of the pathogen. These factors include the components of the disease triangle: environ-

TABLE 1. Mean, median, maximum, and minimum resistance score for each accession

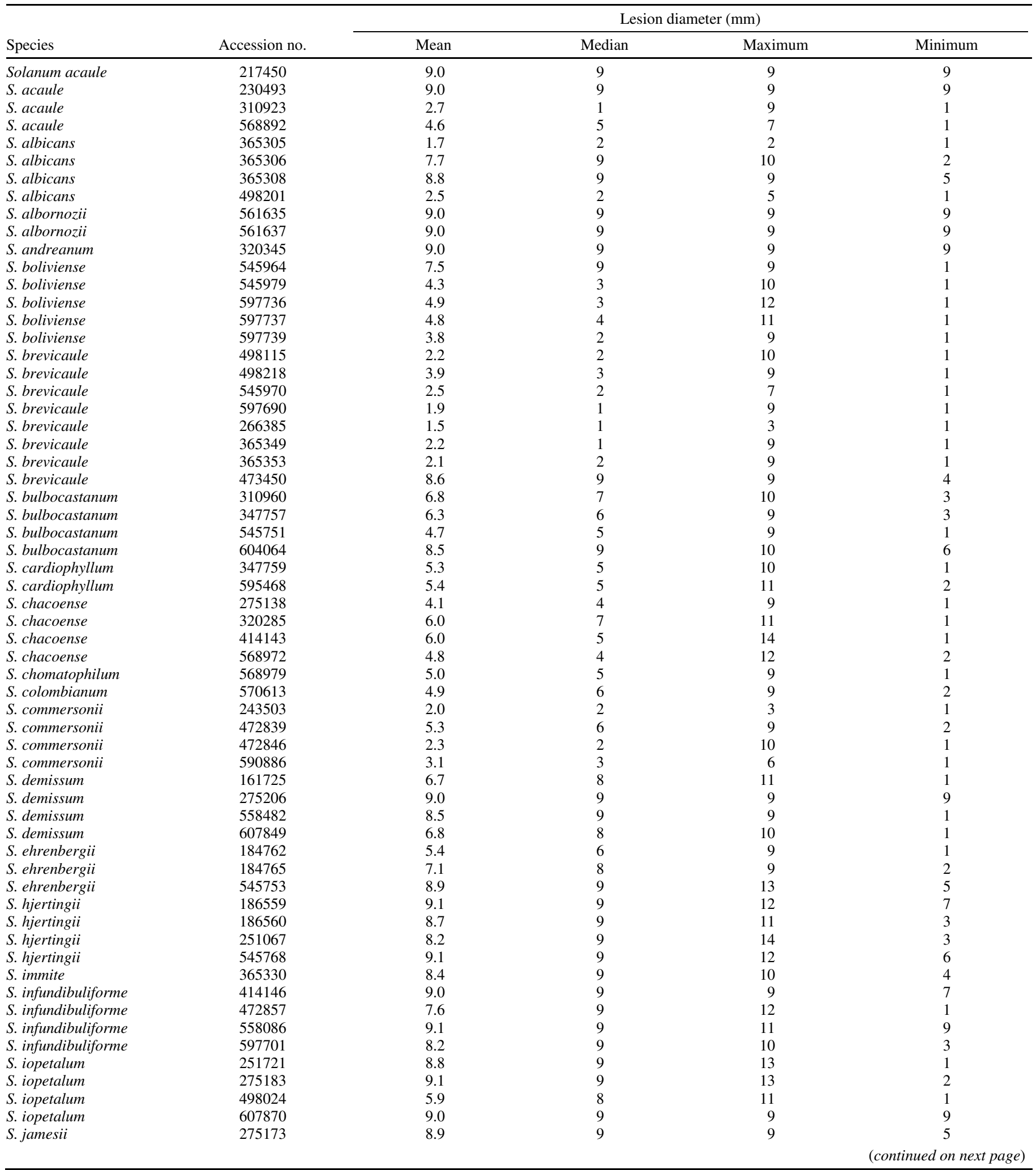


ment, pathogen, and host plant. All three components interact to influence disease severity.

Environment. Populations among and within species are likely to be exposed to different micro- and macroenvironments which may cause different levels of pathogen stress (14) (Supplemental Figures 1 to 4 ). In this study, accessions within a species were selected to represent a wide range of habitats and localities. For example, $S$. acaule is widely distributed in the central and southern Andes (8), and accessions of this species were collected from regions of 65 to $70^{\circ}$ longitude, 17 to $23^{\circ}$ latitude, and 3,700 to $4,560 \mathrm{~m}$ in altitude. At temperatures of 15 to $30^{\circ} \mathrm{C}, P$. carotovorum subsp. carotovorum produces a pectin-degrading enzyme that is involved in pathogenicity; in addition, the number and longevity of bacteria in the soil are reduced at high and low temperature extremes (24). Under high relative humidity, the bacterium can survive for many days on leaves and stems and can overwinter on plant debris (24). This variation in longevity due to environments could affect latent infection of tubers during

TABLE 1. (continued from preceding page)

\begin{tabular}{|c|c|c|c|c|c|}
\hline \multirow[b]{2}{*}{ Species } & \multirow[b]{2}{*}{ Accession no. } & \multicolumn{4}{|c|}{ Lesion diameter (mm) } \\
\hline & & Mean & Median & Maximum & Minimum \\
\hline S. jamesii & 458424 & 9.0 & 9 & 9 & 9 \\
\hline S. jamesii & 595780 & 9.0 & 9 & 9 & 9 \\
\hline S. jamesii & 605368 & 9.0 & 9 & 9 & 9 \\
\hline S. kurtzianum & 442679 & 8.6 & 9 & 14 & 4 \\
\hline S. kurtzianum & 472923 & 8.0 & 9 & 13 & 4 \\
\hline S. kurtzianum & 472960 & 4.9 & 5 & 10 & 1 \\
\hline S. kurtzianum & 558207 & 7.4 & 9 & 13 & 2 \\
\hline S. lesteri & 442694 & 9.0 & 9 & 10 & 9 \\
\hline S. lesteri & 558434 & 8.4 & 9 & 9 & 4 \\
\hline S. lesteri & 558435 & 7.8 & 9 & 13 & 1 \\
\hline S. megistacrolobum & 498257 & 3.3 & 3 & 9 & 1 \\
\hline S. megistacrolobum & 597720 & 7.3 & 9 & 13 & 1 \\
\hline S. megistacrolobum & 607882 & 3.5 & 1 & 10 & 1 \\
\hline S. moscopanum & 473363 & 3.5 & 2 & 12 & 1 \\
\hline S. moscopanum & 500036 & 5.3 & 5 & 9 & 2 \\
\hline S. moscopanum & 545901 & 5.0 & 5 & 12 & 1 \\
\hline S. moscopanum & 567824 & 8.2 & 9 & 9 & 1 \\
\hline S. moscopanum & 570633 & 9.0 & 9 & 9 & 9 \\
\hline S. neorossi & 498401 & 8.3 & 9 & 10 & 2 \\
\hline S. paucijugum & 561650 & 1.1 & 1 & 3 & 1 \\
\hline S. pinnatisectum & 253214 & 6.6 & 7 & 10 & 3 \\
\hline S. pinnatisectum & 275233 & 6.1 & 6 & 8 & 4 \\
\hline S. pinnatisectum & 275235 & 5.8 & 6 & 10 & 2 \\
\hline S. pinnatisectum & 347766 & 5.3 & 5 & 9 & 2 \\
\hline S. polyadenium & 161728 & 8.9 & 9 & 12 & 4 \\
\hline S. polyadenium & 320342 & 6.3 & 6 & 10 & 4 \\
\hline S. polyadenium & 347769 & 5.9 & 6 & 10 & 4 \\
\hline S. polyadenium & 498036 & 9.5 & 10 & 11 & 8 \\
\hline S. raphanifolium & 265862 & 7.6 & 9 & 11 & 1 \\
\hline S. raphanifolium & 473369 & 6.4 & 9 & 11 & 1 \\
\hline S. raphanifolium & 473467 & 5.7 & 6 & 9 & 1 \\
\hline S. raphanifolium & 607883 & 5.6 & 6 & 10 & 1 \\
\hline S. schenckii & 275261 & 6.2 & 9 & 10 & 1 \\
\hline S. schenckii & 498041 & 7.6 & 9 & 13 & 1 \\
\hline S. schenckii & 545790 & 6.7 & 9 & 10 & 1 \\
\hline S. sparsipilum & 310933 & 8.1 & 9 & 11 & 1 \\
\hline S. sparsipilum & 310957 & 3.1 & 2 & 7 & 1 \\
\hline S. sparsipilum & 310959 & 4.3 & 4 & 10 & 1 \\
\hline S. sparsipilum & 597761 & 3.3 & 3 & 12 & 1 \\
\hline S. stenophyllidium & 255527 & 10.3 & 9 & 16 & 8 \\
\hline S. stenophyllidium & 497993 & 9.1 & 9 & 20 & 6 \\
\hline S. stenophyllidium & 545817 & 8.9 & 9 & 11 & 7 \\
\hline S. stenophyllidium & 558460 & 8.0 & 9 & 10 & 1 \\
\hline S. stoloniferum & 497994 & 6.0 & 6 & 10 & 2 \\
\hline S. stoloniferum & 498007 & 7.9 & 9 & 10 & 3 \\
\hline S. stoloniferum & 558450 & 8.1 & 8 & 12 & 3 \\
\hline S. stoloniferum & 558453 & 9.0 & 9 & 9 & 9 \\
\hline S. tarijense & 265577 & 7.9 & 9 & 12 & 2 \\
\hline S. tarijense & 442689 & 6.9 & 7 & 13 & 2 \\
\hline S. tarijense & 558129 & 5.6 & 6 & 13 & 1 \\
\hline S. tarijense & 566799 & 6.8 & 8 & 12 & 1 \\
\hline S. tuquerrense & 561645 & 5.6 & 6 & 9 & 1 \\
\hline S. tuquerrense & 561657 & 10.0 & 9 & 12 & 9 \\
\hline S. verrucosum & 161173 & 1.2 & 1 & 5 & 1 \\
\hline S. verrucosum & 275258 & 3.7 & 3 & 9 & 1 \\
\hline S. verrucosum & 607844 & 7.9 & 9 & 14 & 1 \\
\hline S. verrucosum & 607846 & 2.6 & 1 & 10 & 1 \\
\hline S. verrucosum & 607848 & 2.5 & 1 & 10 & 1 \\
\hline S. violaceimarmoratum & 258856 & 2.4 & 1 & 8 & 1 \\
\hline S. violaceimarmoratum & 473396 & 4.0 & 1 & 9 & 1 \\
\hline S. violaceimarmoratum & 473397 & 3.9 & 2 & 14 & 1 \\
\hline S. violaceimarmoratum & 473398 & 2.3 & 1 & 9 & 1 \\
\hline
\end{tabular}


dormancy. Wet conditions provide bacteria with a better chance for survival, whereas dry conditions shorten the longevity of bacteria. If a dormant potato tuber is physiologically weakened, then bacteria may infect tubers. $P$. carotovorum subsp. carotovorum bacteria can be dispersed by rainfall or by a wide range of insects (20). Also, variability in soil type, organic matter, $\mathrm{pH}$, antagonistic microbe populations, and mineral nutrients influence host-pathogen interactions $(20,21)$. Consequently, variability in pathogen selection pressure can be expected among the sites at which Solanum populations were collected.

Human activities may also influence local disease pressure (Supplemental Figure 1). Reservoirs and ponds can maintain $P$. carotovorum subsp. carotovorum populations (23). Also, debris from potato or other host crops in local fields can provide a concentrated reservoir of $P$. carotovorum subsp. carotovorum. In addition, irrigation in dry areas could allow bacteria to thrive in areas where they would not otherwise do so. For example, resistant accessions of $S$. commersonii were found in agricultural areas. Similarly, in a previous study, accessions resistant to early blight were commonly found in the vicinity of agricultural fields (12).

Pathogen. $P$. carotovorum subsp. carotovorum is a soilborne pathogen. Inoculum dispersal is restricted, leading to a patchy distribution (2). There are two ways to infect plants: local amplification due to transmission from initially infected plants to neighboring plants and dispersal of inoculum by water, insects, or human activity. Soilborne diseases often develop more slowly than airborne diseases (2). The patchy distribution and slow development together could create very heterogeneous selection pressures. In addition, combinations of other factors as described above can generate even more variable selection pressures. However, there is a strong tendency for accessions to be resistant based on local conditions that favor pathogen growth and survival.

P. carotovorum subsp. carotovorum strains vary in their levels of virulence (34). This study evaluated tuber soft rot resistance using only a single isolate, WPP14, which was derived from infected tubers in Wisconsin (34). We do not know the relationship between this strain and those to which wild species are exposed in Central and South America. However, because our resistance evaluations were based on a highly virulent isolate, we maximized the variation in the resistance reaction and identified wild species phenotypes with high levels of resistance.

Host plant. Previous studies have indicated that soft rot resistance has a polygenic inheritance mode, with some quantitative trait loci of relatively strong effect (35). Broad-sense and narrow-sense heritability are high (17). Among the genetic components, additive factors appear to be more important than dominant factors (18).

However, resistance could be conferred by a number of different mechanisms, some of which would not have been detected in this study. For example, plants could escape disease by producing long stolons extending to noninfested areas. Although tubers at the ends of some stolons may become infected, others may avoid contact with the pathogen. This strategy would allow survival in regions where the pathogen is sporadically distributed. However, our study did not evaluate avoidance as a resistance mechanism.

Due to inconsistent pathogen pressure, random mutation, or genetic drift, disease resistance gene frequencies may vary unpredictably among populations. Under strong selection pressure, disease resistance genes may evolve rapidly, even within a few centuries $(4,10)$

Disease resistance is not a consistent characteristic of a species. Disease outbreaks are often sporadic. Consequently, selection pressure for disease resistance may be inconsistent compared with that for abiotic factors such as frost, for which tolerance is sometimes associated with geography in wild Solanum spp. $(7,19)$. The fitness level of a given plant in response to $P$. carotovorum subsp. carotovorum varies with selection pressure across years even within the area where an accession was collected. Thus, disease pressure is not a constant enough factor to charac-

TABLE 2. K value on median score and $P$ value for each species for which more than two accessions were evaluated

\begin{tabular}{|c|c|c|c|c|c|c|c|}
\hline Species & $N^{\mathrm{a}}$ & $\mathrm{K}$ for $\mathrm{AMT}^{\mathrm{b}}$ & Median & $P$ value ${ }^{\mathrm{c}}$ & $\mathrm{K}$ for $\mathrm{AP}^{\mathrm{b}}$ & Median & $P$ value \\
\hline Solanum acaule & 15 & 5.5 & 0.05 & ns & 24.7 & 0.22 & ns \\
\hline S. albicans & 26 & -7.4 & -0.02 & ns & 53.6 & 0.16 & ns \\
\hline S. boliviense & 26 & -0.2 & 0.00 & ns & 138.2 & 0.07 & $* *$ \\
\hline S. brevicaule & 53 & 200.9 & 0.15 & $*$ & 282.7 & 0.21 & $* * *$ \\
\hline S. bukasovii & 39 & 289.2 & 0.39 & $* * *$ & -422.8 & -0.57 & $* * *$ \\
\hline S. bulbocastanum & 41 & 111.6 & 0.14 & $\S$ & 321.5 & 0.39 & $* * *$ \\
\hline S. cardiophyllum & 28 & -5.4 & -0.01 & ns & -1.1 & 0.00 & ns \\
\hline S. chacoense & 41 & -29.7 & -0.04 & ns & 38.7 & 0.05 & ns \\
\hline S. commersonii & 18 & -33.8 & -0.22 & $\S$ & -60.2 & -0.39 & $*$ \\
\hline S. demissum & 42 & -20.7 & -0.02 & ns & -272.2 & -0.32 & $* *$ \\
\hline S. ehrenbergii & 32 & -10.2 & -0.02 & ns & -124.2 & -0.25 & $*$ \\
\hline S. hjertingii & 52 & 57.7 & 0.04 & ns & -362.9 & -0.27 & $* * *$ \\
\hline S. infundibuliforme & 53 & -61.0 & -0.04 & ns & 1.9 & 0.00 & ns \\
\hline S. jamesii & 44 & 0.0 & 0.00 & ns & 0.0 & 0.00 & ns \\
\hline S. kurtzianum & 53 & -346.3 & -0.25 & $* * *$ & -333.6 & -0.24 & $* * *$ \\
\hline S. lesteri & 36 & 16.1 & 0.03 & ns & -220.1 & -0.35 & $* *$ \\
\hline S. megistacrolobum & 29 & 127.8 & 0.31 & $* *$ & -73.1 & -0.18 & $\S$ \\
\hline S. moscopanum & 15 & -6.2 & -0.06 & ns & 3.4 & 0.03 & ns \\
\hline S. pinnatisectum & 26 & 1.7 & 0.01 & ns & 23.4 & 0.07 & ns \\
\hline S. polyadenium & 57 & 45.4 & 0.03 & ns & 637.0 & 0.40 & $* * *$ \\
\hline S. raphanifolium & 53 & 78.7 & 0.06 & ns & -74.6 & -0.05 & ns \\
\hline S. schenckii & 27 & -57.6 & -0.16 & ns & 29.5 & 0.08 & ns \\
\hline S. sparsipilum & 54 & -329.6 & -0.23 & $* * *$ & -342.4 & -0.24 & $* * *$ \\
\hline S. stenophyllidium & 48 & -92.9 & -0.08 & ns & -309.2 & -0.27 & $* * *$ \\
\hline S. stoloniferum & 43 & 96.7 & 0.11 & ns & -144.8 & -0.16 & $*$ \\
\hline S. tarijense & 41 & 179.6 & 0.22 & $*$ & 120.5 & 0.15 & $\S$ \\
\hline S. tuquerrense & 4 & 3.3 & 0.55 & ns & 3.3 & 0.55 & ns \\
\hline S. verrucosum & 64 & 700.6 & 0.35 & $* * *$ & -523.6 & -0.26 & $* * *$ \\
\hline
\end{tabular}

a Number of plants evaluated.

b $\mathrm{AMT}=$ annual mean temperature and $\mathrm{AP}=$ annual precipitation.

${ }^{c}$ For $P$ values: $\S, * * *$, and $* * *$ indicate significant at $P<0.10,0.05,0.01$, and 0.001 , respectively; ns $=$ nonsignificant at $P=0.10$. 
S. bukasovii

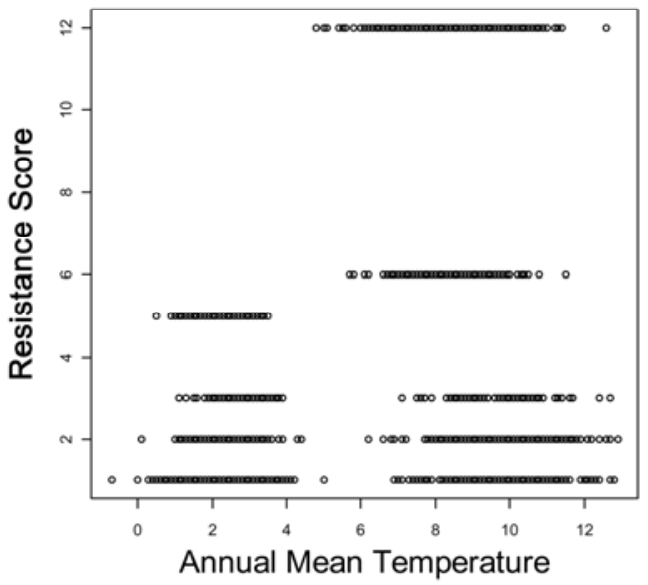

S. jamesii

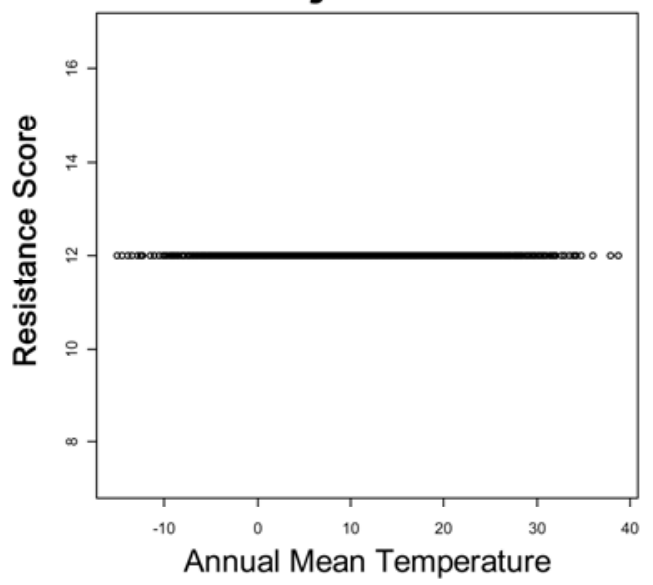

S. bukasovii

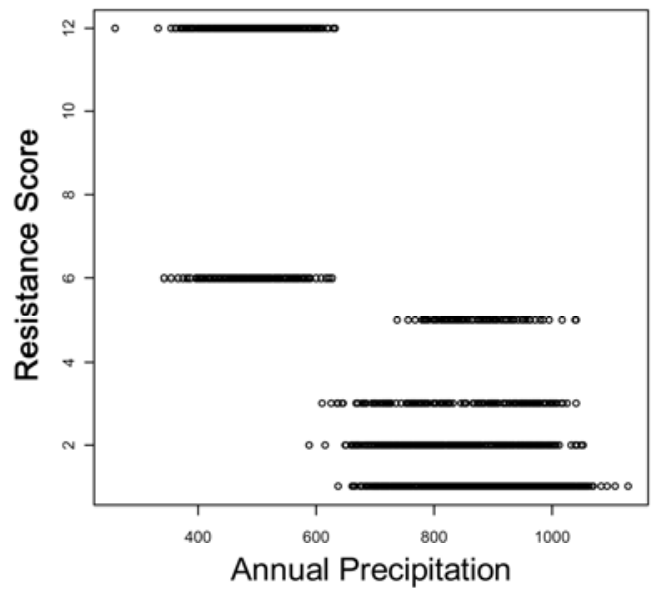

S. jamesii

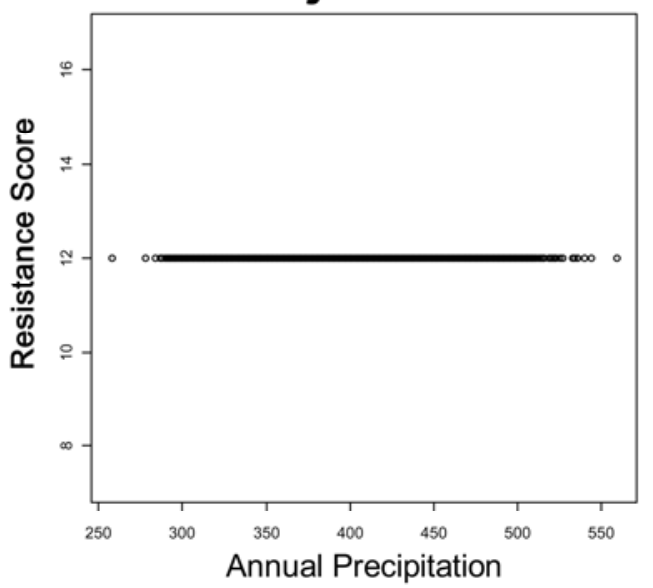

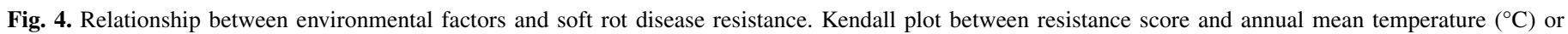
annual precipitation $(\mathrm{mm})$ of two species using simulated data. Data from six accessions of Solanum bukasovii and three accessions of $S$. jamesii were plotted.

\section{S. brevicaule}

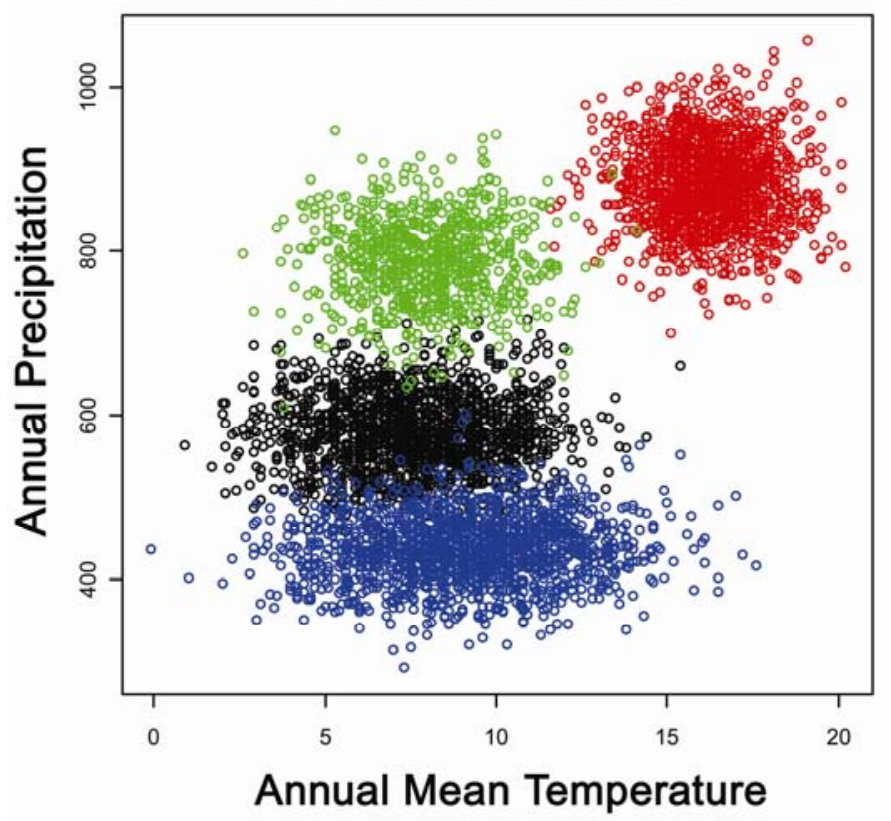

S. raphanifolium

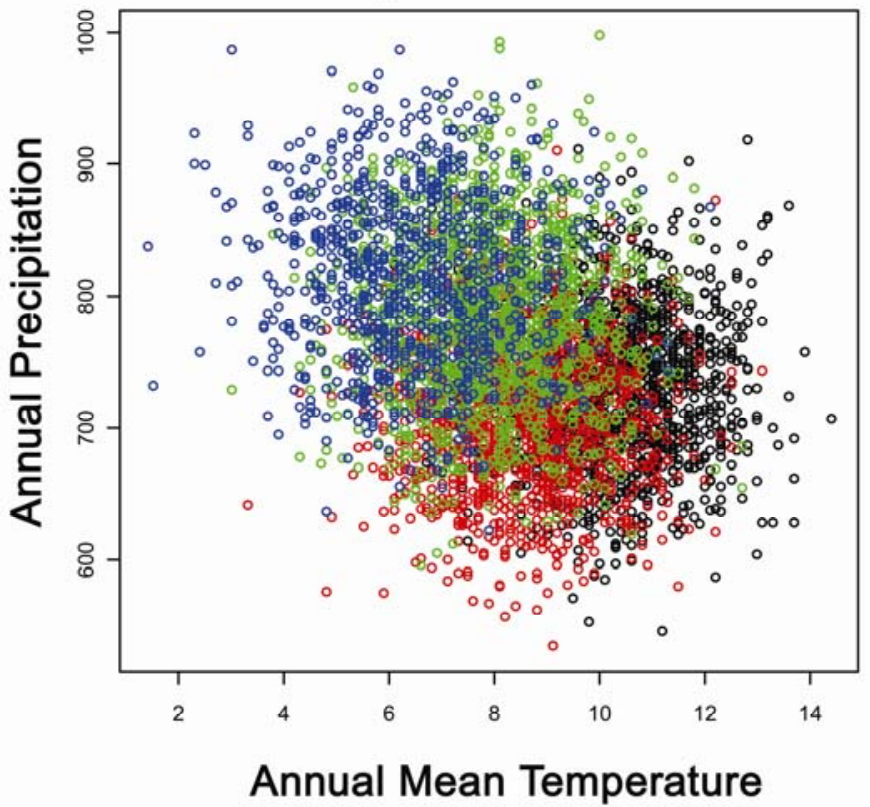

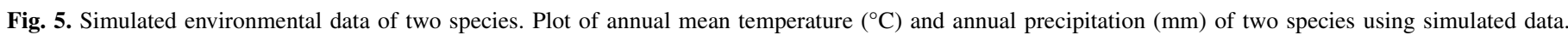
Each color represents a different accession. Solanum brevicaule is resistant and $S$. raphanifolium is moderately susceptible. 
terize disease resistance as a unique trait of a species. In addition, because evolution for disease resistance is still actively and rapidly in progress under local conditions, it may be difficult to find a close relationship between disease resistance and species as well as higher taxonomic levels such as series or EBN, ploidy, and clade. However, considering relevant environmental factors and morphological traits together may provide some predictivity for disease resistance. It is also important to consider the mode of disease resistance. Adaptation would be more difficult with a polygenic inheritance mode with low heritability than with a single gene or a few genes as seen in virus resistance (25). Also, the speed of evolution should be considered. Thus, the favorable environments for disease development as well as the genetic basis of resistance must be determined before pursuing a prediction study.

We may speculate from this study using wild Solanum spp. that other plant species may have a similar story. Disease resistance levels would be similar if populations share the same disease pressures due to specific key factors that maintain a high level of inoculum. Therefore, it may be possible to predict resistance with environmental information that influences selection pressure imposed by a specific pathogen. Furthermore, our study suggests that those species exhibiting phenotypic plasticity in response to temperature and moisture are likely to evolve in response to disease pressure.

\section{ACKNOWLEDGMENTS}

Germplasm was provided by the NRSP-6. We thank P. Crump and N. Keuler, Department of Computing and Biometry, University of Wisconsin-Madison, for assisting with data analysis; M. Ozdogan, University of Wisconsin-Madison, Department of Forest and Wildlife Ecology Geography, for providing the climate data set; and A. Charkowski, Department of Plant Pathology, University of Wisconsin-Madison, for providing the Pectobacterium carotovorum isolate WPP14 and disease screening expertise.

\section{LITERATURE CITED}

1. Chung, Y. S., Sass, M. E., and Nienhuis, J. 2008. Validation of RAPD markers for white mold resistance in two snap bean populations based on field and greenhouse evaluations. Crop Sci. 48:2265-2273.

2. Cooke, B. M., Jones, D. G., and Kaye, B. 2006. The Epidemiology of Plant Diseases, 2nd ed. Springer, The Netherlands.

3. Correll, D. S. 1962. The Potato and Its Wild Relatives. Contr. Texas Res. Foun., Bot. Stud. Renner, TX.

4. Grube, R. C., Radwanski, E. R., and Jahn, M. 2000. Comparative genetics of disease resistance within the Solanaceae. Genetics 155:873-887.

5. Hanneman, R. E. 1994. Assignment of endosperm balance numbers to the tuber-bearing Solanums and their close non-tuber-bearing relatives. Euphytica 74:19-25.

6. Hawkes, J. G. 1990. The Potato-Evolution, Biodiversity and Genetic Resources. Belhaven Press, London.

7. Hijmans, R. J., Jacobs, M., Bamberg, J. B., and Spooner, D. M. 2003. Frost tolerance in wild potato species: Assessing the predictivity of taxonomic, geographic, and ecological factors. Euphytica 130:47-59.

8. Hijmans, R. J., Spooner, D. M., Salas, A. R., and Cruz, J. D. L. 2002. Atlas of Wild Potatoes. International Plant Genetic Resources Institute, Rome.

9. Hollander, M., and Wolfe, D. A. 1999. Nonparametric Statistical Methods, 2nd ed. Wiley Series in Probability and Statistics, New York.

10. Hulbert, S. H., Webb, C. A., Smith, S. M., and Sun, Q. 2001. Resistance gene complexes: Evolution and utilization. Annu. Rev. Phytopathol. 39:285-312.

11. Jansky, S. H., Simon, R., and Spooner, D. M. 2006. A test of taxonomic predictivity: Resistance to white mold in wild relatives of cultivated potato. Crop Sci. 46:2561-2570.
12. Jansky, S. H., Simon, R., and Spooner, D. M. 2008. A test of taxonomic predictivity: Resistance to early blight in wild relatives of cultivated potato. Phytopathology 98:680-687.

13. Jansky, S. H., Simon, R., and Spooner, D. M. 2009. A test of taxonomic predictivity: Resistance to the Colorado potato beetle in wild relatives of cultivated potato. J. Econ. Entomol.102:422-431.

14. Jarosz, A. M., and Burdon, J. J. 1988. The effect of small-scale environmental-changes on disease incidence and severity in a natural plant-pathogen interaction. Oecologia 75:278-281.

15. Kendall, M. G. 1983. A new measure of rank correlation. Biometrika 30:81-93.

16. Kruskal, W. H., and Wallis, W. A. 1952. Use of ranks in one-criterion analysis of variance. J. Am. Stat. Assoc. 47:583-621.

17. Lebecka, R., and Zimnoch-Guzowska, E. 2004. The inheritance of resistance to soft rot Erwinia carotovora subsp. atroseptica) in diploid potato families. Am. J. Potato Res. 81:395-401.

18. Lebecka, R., Zimnoch-Guzowska, E., and Kaczmarek, Z. 2004. Resistance to soft rot Erwinia carotovora subsp. atroseptica) in tetraploid potato families obtained from $4 \mathrm{x}-2 \mathrm{x}$ crosses. Am. J. Potato Res. 82:203210.

19. Li, P. H., Palta, J. P., and Hawkes, J. G. 1980. A scientific noteinterrelationship between frost hardiness and elevation of genotype origin. Am. Potato J. 57:184-185.

20. McGuire, R. G., and Kelman, A. 1984. Reduced severity of Erwinia soft rot in potato tubers with increased calcium content. Phytopathology 74:1250-1256.

21. McGuire, R. G., and Kelman. 1986. Calcium in potato-tuber cell-walls in relation to tissue maceration by Erwinia-carotovora pv. atroseptica. Phytopathology 76:401-406.

22. New, M. G., Hulme, M., and Jones, P. D. 1999. Representing 20th century space-time climate variability. J. Climate 12:829-856.

23. Norman, D. J., Yuen, J. M. F., Resendiz, R., and Boswell, J. 2003. Characterization of Erwinia populations from nursery retention ponds and lakes infecting ornamental plants in Florida. Plant Dis. 87:193-196.

24. Perombelon, M. C. M., and Kelman, A. 1980. Ecology of the soft rot Erwinias. Annu. Rev. Phytopathology 18:361-387.

25. Razdan, M. K., and Mattoo, A. K. 2005. Genetic Improvement of Solanaceous Crops. Science Publishers, Inc., Infield, NH.

26. Rodriguez, F., and Spooner, D. M. 2009. Nitrate reductase phylogeny of potato (Solanum sect. Petota) genomes with emphasis on the origins of the polyploid species. Syst. Bot. 34:207-219.

27. Rose, L. E., Langley, C. H., Bernal, A. J., and Michelmore, R. W. 2005. Natural variation in the Pto pathogen resistance gene within species of wild tomato (Lycopersicon). I. Functional analysis of Pto alleles. Genetics 171:345-357.

28. Schober, B. M., and Zadoks, J. C. 1998. Development of populations of soft rot bacteria on witloof chicory leaves during root production in the field. J. Phytopathol. 146:631-636.

29. Spooner, D., Rodriguez, F., Polgár, Z., Ballard, H. E., and Jansky, S. H. 2008. Genomic origins of potato polyploids: GBSSI gene sequencing data. Plant Genome (Suppl.) Crop Sci. 48:S27-S36.

30. Spooner, D. M., and Castillo, R. 1997. Reexamination of series relationships of South American wild potato (Solanaceae: Solanum sect. Petota): Evidence from chloroplast DNA restriction site variation. Am. J. Bot. 84:671-685.

31. Spooner, D. M., Jansky, S. H., and Simon, R. 2009. Tests of taxonomic and biogeographic predictivity: Resistance to disease and insect pests in wild relatives of cultivated potato. Crop Sci. 49:1367-1376.

32. Spooner, D. M., and Sytsma, K. J. 1992. Reexamination of series relationships of Mexican and Central American wild potatoes (Solanaceae: Solanum sect. Petota): Evidence from chloroplast DNA restriction site variation. Syst. Bot. 17:432-448.

33. Spooner, D. M., van den Berg, R., Rodríquez, A., Bamberg, J. B., Hijmans, R. J., and Lara-Cabrera, S. 2004. Wild potatoes (Solanum section Petota) of North and Central America. Syst. Bot. Monogr. 68:1$209+9 \mathrm{pl}$.

34. Yap, M. N., Barak, J. D., and Charkowski, A. O. 2004. Genomic diversity of Erwinia carotovora subsp. carotovora and its correlation with virulence. Appl. Environ. Microbiol. 70:3013-3023.

35. Zimnoch-Guzowska, E., Marczewski, W., Lebecka, R., Flis, B., SchaferPregl, R., and Gebhardt, C. 2000. QTL analysis of new sources of resistance to Erwinia carotovora ssp. atroseptica in potato done by ALFP, RFLP, and resistance-gene-like markers. Crop Sci. 40:1156-1167. 